\title{
Pengaruh ketinggian bola jatuh terhadap tegangan listrik yang dihasilkan trampolin sebagai pemanen energi dengan pemasangan piezoelektrik
}

\author{
Adhes Gamayel ${ }^{1 *}$, Fajar Mulyana ${ }^{2)}$, \& Ade Sunardi ${ }^{3)}$ \\ 1,3) Jakarta Global University, Grand Depok City, J1 Boulevard Raya No.2 Kota Depok, Jawa Barat 16412 \\ ${ }^{2}$ Politeknik Negeri Jakarta, Jl. Prof. DR. G.A. Siwabessy, Kota Depok, Jawa Barat 16424 \\ Website: jgu.ac.id , E-mail: ade@jgu.ac.id \\ * Penulis Koresponden
}

\begin{abstract}
Abstrak - Piezoelektrik adalah salah satu alat pemanen energi yang menghasilkan energi listrik ketika mengalami defleksi. Defleksi yang terjadi secara terus menerus dengan arah yang berlawanan (atas ke bawah, kanan ke kiri) dinamakan getaran. Peristiwa terjadinya getaran ketika alat olahraga digunakan salah satunya adalah trampolin. Tujuan dari penelitian ini adalah untuk mengindentifikasi potensi penggunaan trampolin sebagai pemanen energi ketika dipasang piezoelektrik. Metode penelitian yang dilakukan adalah mengetahui nilai tegangan listrik dari pengujian jatuhnya bola pada ketinggian 60, 70,80 cm tepat diatas trampolin yang ditempel piezoelektrik pada bagian matras. Hasil pengujian didapatkan bahwa saat dijatuhkan pada ketinggian $60 \mathrm{~cm}$, bola basket menghasilkan 0.93 volt dan bola sepak 0.80 volt. Pada ketinggian $80 \mathrm{~cm}$, bola basket menghasilkan 1.26 volt; dan bola sepak 1.21 volt. Semakin tinggi bola jatuh, maka semakin besar nilai tegangan listrik. Hal ini terjadi karena tinggi posisi jatuh bola dan massa bola berpengaruh terhadap kecepatan bola saat menumbuk matras trampolin. Semakin cepat bola menumbuk trampolin, maka semakin besar momentum tumbukan dan getaran yang terjadi.
\end{abstract}

Kata kunci: trampolin, piezoelektrik, bola, tegangan

\begin{abstract}
Piezoelectric is an energy harvester that produces electrical energy when it is deflected. Deflection that occurs continuously in the opposite direction (top to bottom, left to right) is called vibration. Trampoline is an example for sport equipment that vibrate when it used. This experimental was to identify the potential use of trampoline which piezoelectric was installed as energy harvester. The experiment method that used is measure the electric voltage from falling the ball in various height namely, 60,70,80 cm. Result showed that basketball and football dropped in height $60 \mathrm{~cm}$ produce voltage in 0.93 volt and 0.80 volt respectively. At height of $80 \mathrm{~cm}$, basketball and football dropped and produce 1.26 volt and 1.21 volt respectively. The higher ball dropped; the greater value of voltage will be generated in trampoline. It due to the ball mass and elevated position lead in velocity impact. Higher velocity impact creates large impact momentum and vibration
\end{abstract}

Keyword: trampoline, piezoelectric, ball, voltage

\section{PENDAHULUAN}

Piezoelektrik adalah salah satu alat pemanen energi yang menghasilkan energi listrik ketika mengalami defleksi [1]. Namun, energi listrik yang dihasilkan sangat kecil sehingga membutuhkan media penyimpan energi listrik seperti konduktor dan baterai. Piezoelektrik yang ada dipasaran memiliki dimensi yang relatif kecil dan diperuntukkan pada alat-alat elektronika. Keunggulan piezoelektrik sebagai pemanen energi adalah ramah lingkungan dan hanya membutuhkan getaran untuk menghasilkan listrik. Kekurangan yang dimiliki oleh piezoelektrik adalah Dipresentasikan pada Tanggal 28 November 2020 Copyright $@ 2020$ FT - UHAMKA. - All rights reserved harga yang relatif mahal untuk kapasitas listrik yang besar.

Penelitian terkait piezoelektrik dimulai oleh penulis menggunakan kantilever dengan penambahan bluff body [1]. Hasil dari penelitian ini adalah semakin kecil ukuran bluff body berpenampang segitiga, menyebabkan voltase yang dihasilkan meningkat karena lebih banyak olakan aliran fluida menumbuk piezoelektrik. Penelitian dilanjutkan menggunakan beberapa macam bentuk penampang bluff body seperti penampang kotak, segitiga, segi enam, dan segi delapan untuk peningkatan voltase pada piezoelektrik sistem kantilever [2]. Dari hasil penelitian, didapatkan bahwa DOI: 10.22236/teknoka.v5i.314 
bluff body penampang segi enam mampu menghasilkan tegangan listrik paling tinggi karena olakan udara yang dihasilkan mampu menumbuk kantilever lebih besar dibandingkan dengan bluff body lain.

Pengembangan selanjutnya dalam penelitian piezoelektrik berupa pemanfaatan pantulan bola karet yang digunakan untuk menumbuk piezoelektrik sehingga menghasilkan energi listrik [3]. Hasil penelitian menyimpulkan bahwa ketinggian dan massa bola berpengaruh terhadap tegangan listrik yang dihasilkan oleh piezoelektrik karena energi tumbukan yang dihasilkan besar. Penelitian terkait tumbukan piezoelektrik dilanjutkan pada 2019 dengan memanfaatkan kelereng sebagai media tumbuk piezoelektrik untuk menghasilkan energi listrik [4]. Pada penelitian tersebut didapatkan bahwa semakin besar massa yang dimiliki sebuah kelereng, tumbukan yang terjadi dengan piezoelektrik semakin tinggi dan lendutan yang terjadi besar sehingga voltase yang dihasilkan oleh piezoelektrik juga besar.

Dari uraian penelitian yang telah dilakukan, belum ada implementasi secara langsung kepada alat yang dapat bergetar secara terus menerus. Trampolin adalah salah satu alat olahraga yang mengalami defleksi dan getaran selama trampolin tersebut dimainkan. Tujuan dari penelitian ini untuk mengindentifikasi potensi penggunaan trampolin sebagai pemanen energi ketika dipasang piezoelektrik.

\section{LANDASAN TEORI}

\subsection{Piezoelektrik}

Piezoelektrik adalah material yang menghasilkan tegangan listrik apabila mendapatkan tekanan. Komponen elektronika yang mengalami perubahan energi mekanik menjadi energi listrik biasa disebut tranduser atau aktuator [5]. Polarisasi elektron menyebabkan elektron yang begerak acak menjadi teratur dan terkutub. Akibat polarisasi tersebut, maka timbul tegangan listrik. Semakin besar tekanan yang terjadi, proses polarisasi lebih cepat dan menyebabkan nilai tegangan listrik besar [4]. Begitu juga dengan getaran, akibat adanya penekanan pada arah yang berlawanan, maka akan timbul getaran. Semakin besar tekanan dan semakin sering terjadi getaran, maka potensi tegangan listrik yang dihasilkan piezoelektrik untuk disimpan kedalam baterai atau konduktor semakin cepat. Detail gerak elektron pada piezoelektrik terlihat pada gambar 1 .

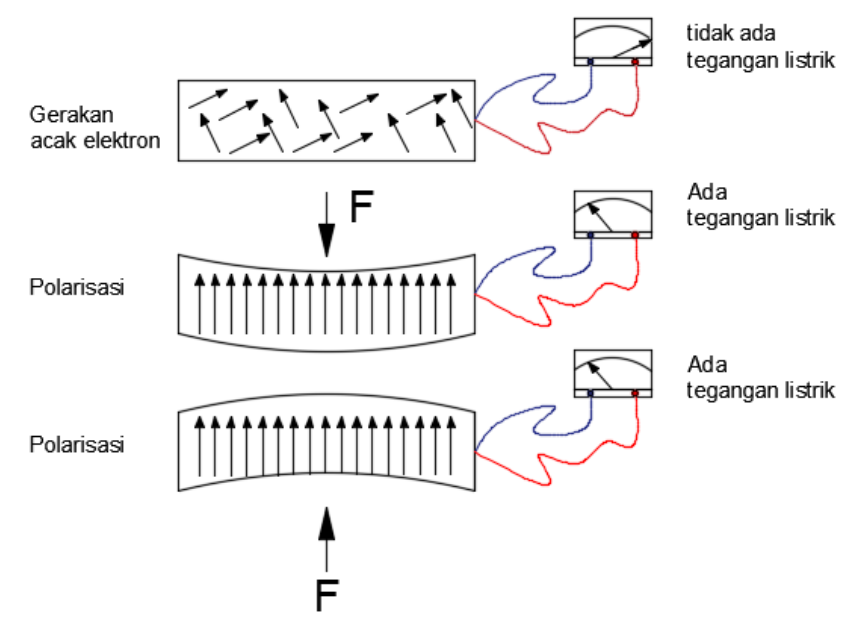

Gambar 1 Posisi elektron di dalam piezoelektrik saat belum ada gaya dan sesaat terkena gaya

\subsection{Trampolin}

Trampolin adalah wahana bermain/alat olahraga yang terdiri dari rangka, pegas, dan matras. Keterikatan matras pada pegas menyebabkan manusia yang bermain diatasnya akan mengalami pantulan atas bawah. Manusia yang bermain trampolin dapat memantul secara simultan karena adanya pergerakan lutut dan engkel kaki. Hal ini berbeda jika yang dijatuhkan adalah sebuah benda dimana benda mengalami pantulan yang tidak terus menerus karena fungsi dari pegas yang bersifat peredaman.

Banyaknya getaran yang terjadi pada trampolin berpotensi menjadi salah satu alat pemanen energi jika dipasang piezoelektrik pada matras. Ilustrasi panen energi pada trampoline dianalogikan dengan sistem pegas massa yang dapat dilihat pada gambar 2, dimana terdapat massa $(\mathrm{m})$, konstanta pegas $(\mathrm{k})$, koefisien redaman mekanis $\left(b_{e}\right)$, dan koefisien redaman induksi listrik $(\Theta)$

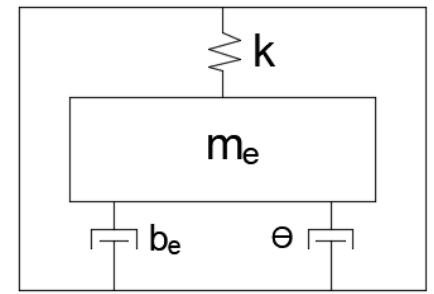

Gambar 2 Sistem piezoelektrik pemanen energi dengan peredaman [6]

Dalam implementasi pada trampolin, besarnya massa, konstanta pegas yang dipengaruhi oleh jumlah pegas dan koefisien redaman mekanis berkaitan dalam pembentukan grafik sinusoidal. Hubungan ketiga faktor tersebut dapat dituliskan dalam persamaan 


$$
\begin{aligned}
z(t) & =A \sin \left(\omega_{n} t\right) \\
\omega_{n} & =\sqrt{\frac{k}{m}}
\end{aligned}
$$

Gaya tekan pada matras yang terhubung dengan pegas akan mengakibatnya adanya defleksi dan getaran. Gaya dan pegas dapat dihubungkan dengan persamaan (3), dimana $\mathrm{F}$ adalah gaya tekan, a adalah konstanta pegas linier, $\mathrm{b}$ adalah konstanta pegas nonlinier

$$
F=a x+b x^{3} ; a>0
$$

Nilai $\mathrm{b}>0$ jika pegas yang dipakai termasuk jenis hard spring. Nilai $\mathrm{b}=0$ digunakan jika memakai pegas jenis linier spring. Nilai $b<0$, jika menggunakan pegas jenis soft spring. Hubungan antara jenis pegas dan gaya tekan dapat dilihat pada gambar 3.

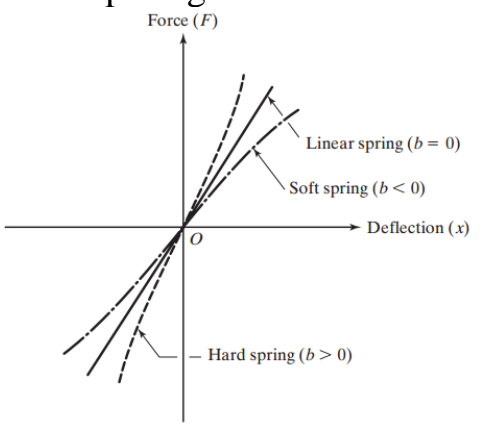

Gambar 3 Gaya tekan dan jenis pegas [7]

\subsection{Energi Mekanik}

Implementasi bola jatuh dalam persamaan kekekalan energi, tertulis pada persamaan dibawah ini

$$
\begin{aligned}
E M_{1} & =E M_{2} \\
E P_{1}+E K_{1} & =E P_{2}+E K_{2}
\end{aligned}
$$

Pada kondisi sebelum benda jatuh, tidak ada energi kinetik karena kecepatannya adalah nol $\left(\mathrm{EK}_{1}=0\right)$.

Sesaat ketika benda tepat menyentuh tanah, tidak ada energi potensial karena nilai ketinggian adalah nol, $\left(\mathrm{EP}_{2}=0\right)$

Dari kedua kondisi diatas, kecepatan sesaat sebelum menyentuh tanah dapat dihitung yaitu

$$
\begin{gathered}
E P_{1}=E K_{2} \\
m \cdot g \cdot h_{1}=\frac{1}{2} m \cdot v^{2} \\
\sqrt{2 \cdot g \cdot h_{1}}=v
\end{gathered}
$$

Dari persamaan (8) dapat disimpulkan bahwa kecepatan sesaat benda sebelum menyentuh tanah tergantung dari ketinggian yang dimilikinya. Semakin tinggi suatu benda dijatuhkan, maka semakin tinggi kecepatan yang dihasilkan.

Gerakan bola memantul dalam trampolin termasuk dalam elastis sebagian dan terhubung pada hukum momentum. Momentum adalah kecenderungan benda yang bergerak untuk melanjutkan gerakannya pada kelajuan yang konstan. Momentum merupakan besaran vektor yang searah dengan kecepatan benda. Secara matematis dituliskan [8]

$$
P=m \cdot v
$$

Dimana

$$
\begin{aligned}
\mathrm{P} & =\operatorname{Momentum}(\mathrm{kg} \cdot \mathrm{m} / \mathrm{s}) \\
\mathrm{m} & =\operatorname{Massa}(\mathrm{kg}) \\
\mathrm{v} & =\operatorname{kecepatan}(\mathrm{m} / \mathrm{s})
\end{aligned}
$$

momentum terhubung juga dengan impuls dimana secara matematis tertulis

$$
\begin{gathered}
I=\Delta P \\
F \cdot \Delta t=m \cdot \Delta v
\end{gathered}
$$

Dari persamaan (9), (10) dan (11) terlihat jelas bahwa nilai massa dapat mempengaruhi gaya dan besarnya momentum tumbukan. Pada persamaan (1) massa terhubung dengan besarnya nilai sinus yang secara analogi sama dengan persamaan (12) yaitu tegangan sinusoidal.

$$
V(t)=V_{\max } \sin \left(\omega_{n} t+\varphi\right)
$$

Sesuai dengan persamaan (1), (2), dan (12), didapatkan hubungan antara voltase, frekuensi, dan massa. Semakin besar nilai massa, maka sinus menjadi kecil dan nilai grafik sinusoidalnya menjadi besar.

\section{METODOLOGI PENELITIAN}

\subsection{Metode penelitian}

Penelitian yang dilakukan yaitu mengukur tegangan listrik dari bola yang dijatuhkan secara langsung ke trampolin pada ketinggian $60,70,80 \mathrm{~cm}$. Bola yang digunakan adalah bola basket dan bola sepak. Grafik yang ditampilkan berupa grafik sinusoidal pada satu kali tumbukan, dan grafik hubungan tinggi jatuh bolavoltase. 


\subsection{Alat, Bahan, dan Instalasi Penelitian}

Trampolin yang digunakan dalam penelitian ini berbentuk lingkaran dengan diameter $95 \mathrm{~cm}$ dengan tinggi diatas tanah berjarak $20 \mathrm{~cm}$. Piezoelektrik yang dipakai berbahan keramik berbentuk keeping dengan diameter $35 \mathrm{~mm}$ berjumlah 16 buah. Piezoelektrik ini ditempel pada sponeva berukuran 30x30 cm dengan rangkaian seri susunan antar piezoelektrik adalah 4 baris dan 4 kolom. Detail trampoline dan peletakan piezoelektrik pada sponeva dapat dilihat pada gambar 4.

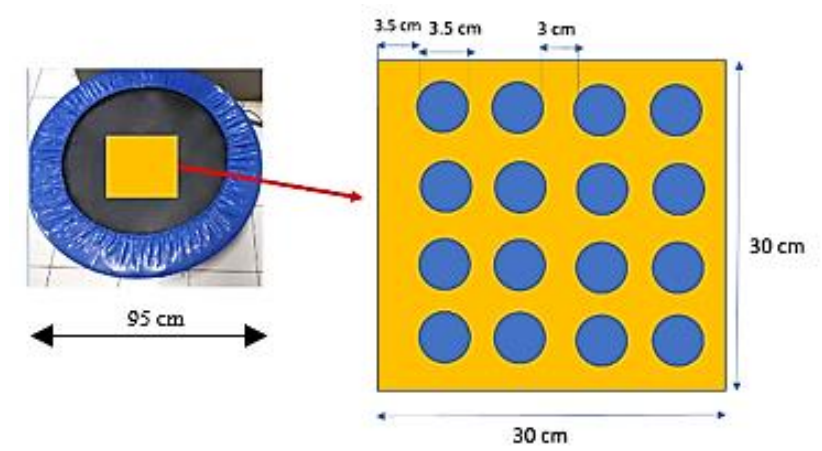

Gambar 4 Detail trampoline dan rangkaian seri piezoelektrik pada sponeva

Sponeva yang telah tersusun piezoelektrik kemudian ditempel pada bagian bawah matras trampolin. Tujuan piezoelektrik dipasang pada permukaan sponeva agar piezoelektrik tidak mudah rusak akibat tumbukan langsung yang ditimbulkan oleh trampolin. Rangkaian piezoelektrik dihubungkan langsung dengan DATAQ untuk dapat merekam data tumbukan yang terjadi. Waktu pengambilan data tegangan listrik pada DATAQ adalah 0.04 detik setiap data. Hasil dari DATAQ dikonversikan ke dalam microsoft excel agar lebih mudah dalam pembuatan grafik. Detail instalasi penelitian dapat dilihat pada gambar 5.

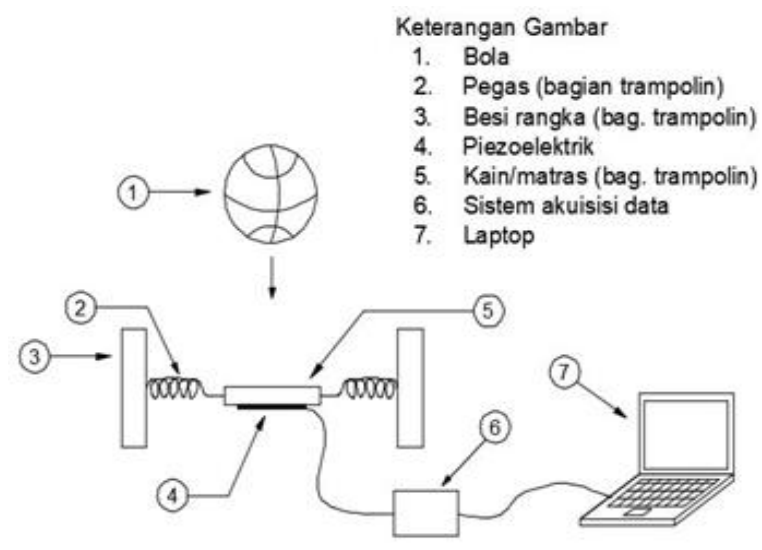

Copyright (C) 2020 FT-UHAMKA. - All rights reserved DOI: 10.22236/teknoka.v5i.314
Gambar 5 Instalasi Penelitian

\section{HASIL DAN PEMBAHASAN}

Grafik sinusoidal dari satu tumbukan pada bola basket di masing-masing ketinggian dapat dilihat pada gambar 6 .

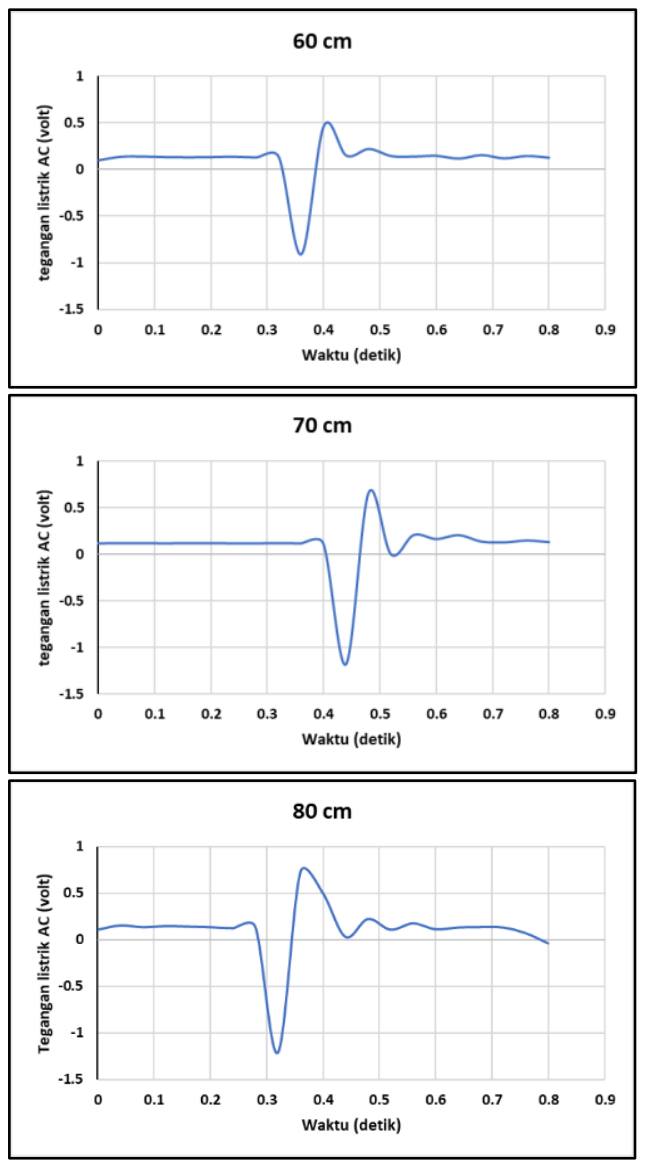

Gambar 6 Tegangan listrik yang dihasilkan dari tumbukan bola basket pada ketinggian 60,70,80 cm.

Sesuai pada gambar 6, terjadi satu kali tumbukan bola jatuh terhadap matras trampolin. Pembacaan pada DATAQ menyatakan bahwa timbul tegangan listrik dengan melendutnya matras ke arah bawah akibat tumbukan bola basket. Secara aktual, tegangan listrik yang dihasilkan memiliki arus bolak balik, sehingga nilai tegangan listrik yang bertanda minus sebenarnya adalah absolut. Semakin tinggi bola basket jatuh menumbuk matras trampolin, maka semakin besar nilai tegangan listrik yang dihasilkan. Sesuai dengan fungsinya, trampoline memiliki matras yang dikaitkan dengan pegas agar terjadi lendutan secara berulangulang. Dengan area lendutan yang luas dan ukuran bola yang besar, maka lendutan yang terjadi cenderung besar sehingga menghasilkan tegangan listrik yang tinggi. Grafik pada semua ketinggian menerangkan 
bahwa pantulan bola yang terjadi satu kali akan diikuti dengan pantulan yang semakin mengecil. Hal itu terlihat jelas bahwa fungsi pegas pada trampolin menjadi peredam bagi benda yang terpantul.

Grafik sinusoidal pada bola sepak dapat dilihat di gambar 7, dimana pola grafik sama dengan yang dimiliki oleh bola basket di berbagai ketinggian.
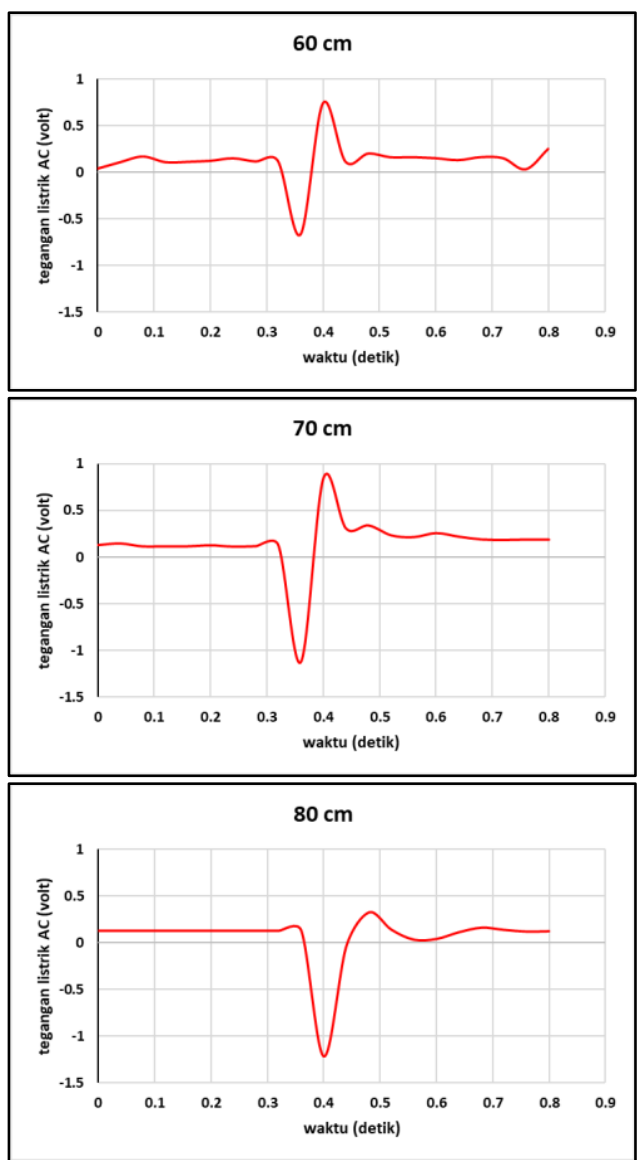

Gambar 7 Tegangan listrik yang dihasilkan dari tumbukan bola sepak pada ketinggian 60,70, $80 \mathrm{~cm}$.

Tegangan listrik yang dihasilkan dari bola sepak pada ketinggian jatuh $80 \mathrm{~cm}$ adalah yang paling tinggi. Hal ini terjadi karena semakin tinggi bola sepak dijatuhkan, maka terjadi perubahan energi dari energi potensial menjadi energi kinetik, dimana kecepatan semakin mendekati matras akan semakin tinggi. Pada saat bola menumbuk matras, kecepatan dan massa bola berpengaruh karena adanya momentum tumbukan. Matras terikat dengan pegas yang memiliki konstanta peredaman, sehingga sesaat setelah tumbukan, matras mengalami lendutan hingga pegas dapat memberikan gaya balik dan menarik matras ke posisi semula. Bola memiliki tekanan udara di dalam, sehingga tumbukan dengan matras mengakibatkan bola kembali memantul ke atas walaupun ketinggiannya tidak seperti ketinggian saat menumbuk.
Terbentuknya grafik sinusoidal ketika bola jatuh menumbuk trampoline disesuaikan dengan terjadinya gerakan naik turun matras yang menempel pada trampolin. Ilustrasi dapat dilihat pada gambar 8 berikut.

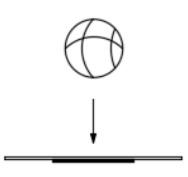

(a)

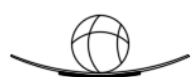

(b)

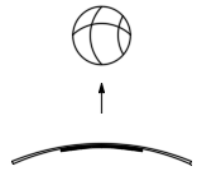

(c)

$\begin{array}{lll}\text { posisi bola } & \text { posisi bola } & \text { posisi bola } \\ \text { akan } & \text { telah } & \text { memantul } \\ \text { menumbuk } & \text { menumbuk } & \end{array}$

Gambar 8 Posisi matras saat menumbuk dan terpelanting

\section{(c)}

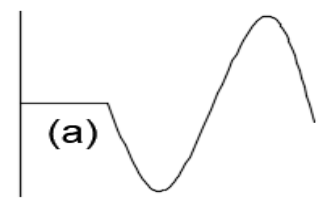

(b)

Gambar 9 Pembentukan grafik sinusoidal berdasarkan posisi bola dan matras di gambar 8.

Pada gambar 9 terlihat pola grafik sinusoidal terjadi akibat adanya tumbukan bola dan saat bola memantul keatas. Saat terjadi tumbukan bola dan menyebabkan matras melendut kearah bawah, terjadi nilai tegangan listrik minus. Ketika memantul, matras melendut ke arah atas sehingga terjadi nilai tegangan positif. Dalam grafik sinusoidal terbentuk satu gelombang yaitu satu lembah dan satu bukit dalam suatu waktu tertentu yang dinamakan periode. Pada gambar 6 dan 7, periode dan frekuensi yang didapatkan sesuai tabel 1 berikut ini.

Tabel 1 Periode dan frekuensi jatuh bola

\begin{tabular}{c|l|l|l|l}
\hline ketinggian & \multicolumn{2}{|c|}{ bola basket } & \multicolumn{2}{c}{ bola sepak } \\
\hline$(\mathrm{cm})$ & $\mathrm{T}(\mathrm{s})$ & $\mathrm{f}(\mathrm{Hz})$ & $\mathrm{T}(\mathrm{s})$ & $\mathrm{f}(\mathrm{Hz})$ \\
\hline 60 & 0.12 & 8.34 & 0.12 & 8.34 \\
\hline 70 & 0.12 & 8.34 & 0.12 & 8.34 \\
\hline 80 & 0.16 & 6.25 & 0.2 & 5 \\
\hline
\end{tabular}

Sesuai persamaan (1) dan (2), massa bola berpengaruh terhadap periode dan frekuensi terlihat pada ketinggian jatuh $80 \mathrm{~cm}$. Bola basket memiliki massa yang lebih berat sehingga waktu pembentukan satu gelombang lebih singkat dibandingkan dengan bola sepak 


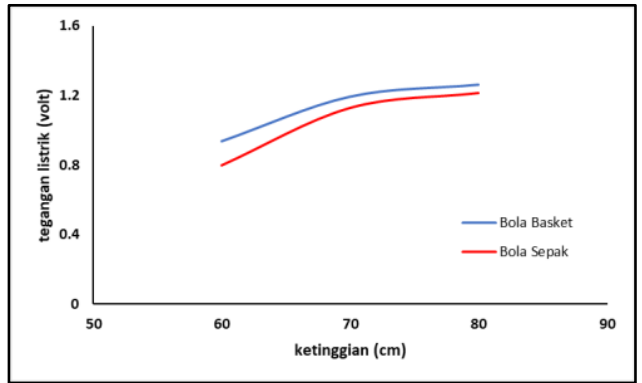

Gambar 10 Hubungan ketinggian bola jatuh dan tegangan listrik yang dihasilkan

Hubungan antara ketinggian bola jatuh dan tegangan listrik yang dihasilkan, dapat dilihat pada gambar 10 . Berdasarkan ketinggian jatuh bola, gambar 10 menjelaskan bahwa pada ketinggian $60 \mathrm{~cm}$, bola basket menghasilkan tegangan listrik 0.93 volt dan tegangan listrik yang dihasilkan bola sepak 0.80 volt. Bola basket mampu menghasilkan tegangan listrik terbesar yaitu 1.26 volt. Bola sepak pada ketinggian $80 \mathrm{~cm}$ menghasilkan tegangan listrik 1.21 volt. Hal ini terkait dengan momentum tumbukan yang terjadi dimana massa dan kecepatan berpengaruh besar terhadap lendutan yang dihasilkan.

\section{SIMPULAN}

Simpulan yang dapat diambil dari pembahasan adalah:

1. Ketinggian bola jatuh memiliki hubungan dengan tegangan listrik yang dihasilkan. Pada ketinggian $60 \mathrm{~cm}$, bola basket menghasilkan tegangan listrik 0.93 volt dan bola sepak 0.80 volt. Hal ini terjadi karena massa dan kecepatan menumbuk bola basket lebih besar daripada bola sepak

2. Tegangan listrik terbesar yaitu 1.26 volt dihasilkan pada bola basket dengan ketinggian jatuh $80 \mathrm{~cm}$. Hal ini terjadi karena semakin tinggi letak suatu benda dijatuhkan, maka kecepatan menumbuk semakin tinggi sehingga saat bertumbuk dengan matras trampolin, akan terjadi lendutan yang besar.

\section{KEPUSTAKAAN}

[1] Kasum K, Mulyana F, Gamayel A. Piezoelektrik Sebagai Pemanen Energi Dengan Penambahan Bluff Body Segitiga. Simetris J Tek Mesin, Elektro Dan Ilmu Komput 2018. https://doi.org/10.24176/simet.v9i2.2291.

[2] Gamayel A. Panen Energi Menggunakan Piezoelektrik Sistem Kantilever Dengan Penambahan Bluff Body. J Tek Mesin 2017;6:273. https://doi.org/10.22441/jtm.v6i4.2105.

[3] Sunard A, Gamayel A. Pemanfaatan Pantulan Bola Karet sebagai Pemanen Energi pada Piezoelektrik. Pros Semin Nas Teknoka 2019. https://doi.org/10.22236/teknoka.v3i0.2914.

[4] Gamayel A, Hariyanto H, Supriadi A, Komalasari K. Pemanfaatan Kelereng sebagai Media Tumbuk pada Piezoelektrik Pemanen Energi. Semin. Nas. Teknoka, vol. 4, Jakarta: Fakultas Teknik UHAMKA; 2019, p. 15-9. https://doi.org/10.22236/teknoka.v.

[5] Yulianti E, Triwahyuni D, Ahda S, Deswita. Pembuatan Bahan Piezoelektrik Ramah Lingkungan Bi0,5Na0,5TiO3 Dengan Metode Molten Salt. J Sains Mater Indones 2012;14:137.

[6] Kundu S, Nemade HB. Modeling and Simulation of a Piezoelectric Vibration Energy Harvester. Procedia Eng 2016;144:568-75. https://doi.org/10.1016/j.proeng.2016.05.043.

[7] Rao SS. Mechanical Vibrations Fifth Edition in SI Units. Mech Vib 2011:62.

[8] Young HD, Freedman RA, Juliastuti E. Fisika Unversitas. Kesepuluh ed. Wibi H, Simarmata L, Safitri A, editors. Jakarta: Erlangga; 2002. 